\title{
Nonattachment, Trait Mindfulness, Meditation Practice and Life Satisfaction: Testing the Buddhism Psychology Model in Indonesia
}

\author{
Yohanes Budiarto \\ Tarumanagara University, Faculty of Psychology, INDONESIA
}

Received 22 February 2019 • Revised 10 June 2019 • Accepted 20 June 2019

\begin{abstract}
This study aimed at studying the path analysis of Buddhism psychology: trait mindfulness and nonattachment. The mindfulness was expected to predict nonattachment and indirectly predicted the psychological needs satisfaction and well-being. The total sample of 229 participants (68.6\% female, 31.4\% male; mean age $\mathrm{M}=18.917, \mathrm{SD}=.699 ; 63.3 \%$ meditation practitioners and $36.7 \%$ non-practitioners) completed the Nonattachment scale, Mindful Attention Awareness Scale (MAAS), basic psychological need satisfaction and well-being. Results confirmed adequate measurement model (composite reliability and convergence validity), as well as significant path within the structural model test. Trait mindfulness predicted nonattachment significantly; nonattachment predicted the psychological need satisfaction; and psychological need satisfaction influence the well-being. Specific indirect effects were also found: nonattachment mediated the path of trait mindfulness and psychological need satisfaction; nonattachment predicted well-being through psychological need satisfaction; and nonattachment and psychological need satisfaction mediated the relationship between trait mindfulness and well-being. Meditation experiences significantly differentiate the prediction of trait mindfulness toward nonattachment.
\end{abstract}

Keywords: trait mindfulness, nonattachment, psychological need satisfaction, well-being.

\section{Introduction}

Within Western tradition, research related to life satisfaction has its origin in $18^{\text {th }}$ century "enlightenment" thinking. From this perspective, life itself became the focus of human life, not service to the King or God. Since then self-actualization and happiness have become prominent, and in the 1960 s life satisfaction became a common topic in survey research (Veenhoven, 1996). Life satisfaction has diverse perspectives, including from Eastern religious perspective. In the concept of Buddhism, the term dukkha is known when talking about human life. The central question in Buddhism is, "Why do we suffer?" "Why is our life unsatisfying and filled with sadness?" "Why is our hope rarely borne fruit?" Historically, Gautama Buddha was believed to have left a luxury life which was his privilege, to get answers to questions about life suffering and life satisfaction. The answers he found, which made him a Buddha, were encapsulated in the "Four Noble Truths", or some scientists refer to them as "The Truth for Noble People”.

(C) Authors. Terms and conditions of Creative Commons Attribution 4.0 International (CC BY 4.0) apply. Correspondence: Yohanes Budiarto, Tarumanagara University, Faculty of Psychology, Gedung K. Lt.2, Jl. Letjen S. Parman No. 1 Jakarta Barat 11440, INDONESIA. E-mail: yohanesb@fpsi.untar.ac.id. 
The Four Noble Truths are the fundamental orientation of Buddhism. The first truth is that life is suffering which in Pali is written dukkha. The second truth clarifies the reason for affliction or unsatisfactory in life, namely attachment; the third truth is the effort to cease from suffering; and finally, the fourth Truth is related to the way to stop dukkha. The term dukkha refers to pain, distress, anxiety, and dissatisfaction felt physically and mentally. The emergence of dukkha in human life is caused by the desire, craving for something, and attachment (Tsering, 2005).

- Meditation practices moderating the relationship of participants' trait mindfulness and nonattachment.

- Nonattachment mediated the relationship among trait mindfulness, psychological needs satisfaction, and well-being.

- The Buddhism psychology is proven beneficial to achieve basic psychological needs satisfaction and well-being.

The fundamental idea of Buddhism is that life is characterized by dissatisfaction and imperfection. As a consequence of this claim, our psychological tendency to hold on to pleasant things and fight pain is ultimately futile. In step with Buddhism, attachment to all phenomena is negative due to the fact impermanence and non-self are the highest truths of the universe (Mikulas, 2007). Focusing on anything is the consequence of the world's idea of ignorance and thus welcomes suffering. The Buddha is acutely aware of the impermanent and hollow of the world, as well as unstable nature of the universe, and thus realizes that holding a particular state is unnecessary because self and non-self are illusory. As a result, well-being is caused by a balanced state that is not affected by the external or internal stimulus; in other words, welfare does not depend on certain circumstances (Sahdra, Shaver \& Brown, 2010; Wallace \& Shapiro, 2006).

One concept in Buddhism that is used in overcoming dissatisfaction in life (dukkha) is nonattachment. Experts speculate that nonattachment will contribute to the mental health of individuals, primarily by acting as a protective factor of negative psychological pressure and negative affect. More precisely, suffering mostly stems from ignorance of the mind. Nonattachment is recommended by Buddhism to address obliviousness and reestablish a reasonable state free from uneasiness, dissatisfaction, and gloom (Sahdra, et al., 2010; Wallace \& Shapiro, 2006).

Nonattachment is a key aspect of mindfulness that can be learnt or taught independently from the practice of mindfulness itself. This concept includes the acceptance and release of negative thoughts and feelings (Sahdra et al., 2010). Coffey and Hartman (2008) proposed the possibility that nonattachment may assume an imperative task in the component of how mindfulness influences positive mental adjustment. The concept of nonattachment revolves around a person's thoughts and feelings, and how one must remain aware of unpleasant, neutral and positive aspects of thoughts and feelings without getting too close or pushing too far (Sahdra et al., 2010). Through this process, nonattachment practitioners will know whether they are fixated on mental images related to people, property, or ideas which they hope will be according to their wishes (e.g. Nagarjuna, $2^{\text {nd }}$ century BC / 1995).

The attachment causing suffering is reflected in Buddhism from the four noble truths, which are described as consisting of the truth of suffering, the origin of suffering, the final truth of suffering, and the truth of the path to the end of suffering (Schuhmacher \& Woerner, 1994). In Buddhism, life is considered unsatisfactory, temporary, contains all kinds of suffering, and all pleasant experiences are impermanent (Chen, 2006). The individual's attachment to experiencing pleasure or avoiding pain makes the individual in the cycle of suffering. Suffering can be suppressed through insubordination and elimination of desire and mindfulness (Schuhmacher \& Woerner, 1994). 
The construction of nonattachment is at least as vintage as mindfulness within the Eastern contemplative culture. However, nonattachment is a relative newcomer within the psychology literature, with the first empirical investigation posted with the advent of the Nonattachment Scale, or NAS (Sahdra, Shaver \& Brown, 2010). Nonattachment can be defined as a bendy and balanced manner associated with one's experience without attaching or pressing them (Sahdra et al., 2015; Sahdra \& Shaver, 2013; Sahdra et al., 2010). On the other hand, mindfulness is often defined as paying attention to goals at this time while refraining from judgment and impulsive reactions (Kabat-Zinn \& Hanh, 2009).

Both of these constructs have a very positive impact on a person's psychological condition. Nonattachment has a positive correlation with moderate to strong strengths with life satisfaction. Conversely, it negatively correlated with negative affect and psychological distress (Wang, Wong \& Yeh, 2016). When someone is not bound, his/her sense of well-being is felt to be independent of particular circumstances.

Other supporting findings related to the relationship between nonattachment and well-being can be seen in its positive correlations with subjective well-being (life satisfaction and emotional trait) and emotional well-being (i.e., self-acceptance, personal growth, positive relationships with others, and purpose in life). On the other hand, nonattachment negatively correlated with depression, anxiety, stress, and difficulty in the regulation of emotions. In line with Buddhism's theory that nonattachment could promote positive interpersonal functions, nonattachment positively correlated with empathy and generosity.

The volume of publications related to mindfulness had increased exponentially over the past two decades, resulting in almost 500 new publications in 2012 alone (Black, 2013). This number was expected to increase because more than 300 clinical trials related to mindfulness began to publish the results. The momentum that drives this research is needed. Many of the benefits of psychological health and physical health have been linked to mindfulness training (e.g., Chiesa \& Serretti, 2010; Greeson, 2009; Hofmann et al., 2010; Keng, Smoski, \& Robins, 2011; Smith et al., 2005) and mindfulness trait (e.g. Coffey \& Hartman, 2008; Creswell et al., 2007). Mindfulness is defined as "awareness that arises through attention to purpose, at present, and without judgment until when the experience opened from time to time" (Kabat-Zinn, 2003: 145). Mindfulness, in other words, means paying attention to what is happening within us, for us, and around us.

Existing literature shows that mindfulness is useful for life satisfaction which refers to an individual's global cognitive evaluation of satisfaction with the life of the individual itself as a whole (Diener, Oishi \& Lucas, 2003). Correlational studies have shown that measurement of mindfulness trait is associated with high levels of life satisfaction and low psychological stress, for example, depression, stress (e.g., Brown \& Ryan, 2003; Howell et al., 2008; Schutte \& Malouff, 2011).

The relationship between mindfulness and life satisfaction had been established, but potential mechanisms that might explain this relationship were still unclear, although some ideas explaining how mindfulness showed beneficial effects on subjective well-being had been increasing in the research literature.

Theoretical and empirical research have provided support that the core practices of Buddhist meditation, mindfulness, nonattachment, and self-compassion play important roles in aspects of mental health such as psychological flexibility (e.g., Fletcher et al., 2010; Hayes, 2002; Sahdra, Shaver \& Brown, 2010). Because in everyday life Buddhists focus on these practices, they may show higher psychological flexibility than non-Buddhists.

Various studies have not firmly placed nonattachment position in research related to mental health. Brown et al. (2007) reported that mindfulness predicted nonattachment toward 
mental fixation. Meanwhile, Sahdra et al. (2016) showed that nonattachment acted as a mediator between mindfulness and well-being. Besides that, Sahdra also found that when controlling the role of mindfulness, nonattachment gave a variance value of $7 \%$ to life satisfaction. Although it has a positive impact on the quality of a person's psychological condition, research involving nonattachment is still rare.

Nonattachment is one of the recommended ways in Buddhism that enables humans to reduce life's misery or dissatisfaction. Thus, nonattachment also predicts daily well-being, because satisfaction with life is a component in daily well-being. The psychological mechanism of nonattachment appears more in individuals who practice meditation. The findings of the study by Sahdra et al. (2010) show that meditation practitioners have higher nonattachment than those who are not practitioners. Also, the duration of meditation is positively correlated with nonattachment. Fulfillment of individual daily well-being can be determined by satisfaction with fulfilling basic psychological needs consisting of relatedness, autonomy, and competence. The higher the individuals' relatedness, autonomy, and competence, the higher their wellbeing is.

\section{Method \\ 2.1 Participant}

The study participants had an age range from 18-20 years $(\mathrm{M}=18.917$; $\mathrm{SD}=0.699)$. The majority of participants were female, as many as 157 people (68.6\%) and male as many as 72 people (31.4\%). One hundred forty-five participants (63.3\%) practiced meditation, and eighty-four participants had never meditated (36.7\%).

\subsection{Measurement}

The first questionnaire used in this study was daily well-being survey and daily psychological needs satisfaction, which were arranged based on six different constructs, each construct measured by two items: (a) satisfaction with the day spent (adapted from Satisfacton with Life Scale / SWLS): "Today is a very satisfying day for me" and "Today is an ideal day for me"; (b) positive affect (two-item adaptation of PANAS-X; Watson and Clark, 1994): "I experience a lot of fun today" and "Today is a pleasant day"; (c) negative affect (adaptation of two items from PANAS-X): "Today is a day that frustrates me" and "I am very worried today"; (d) autonomy (adapted from the Basic Need Satisfaction in Life Scale [BNSNLS]): "I managed to get what I needed today" and "I made progress to achieve my goals today"; (e) competencies (adapted from BNSLS, Kashdan et al., 2006): "Today I get new knowledge" and "What I do today improves my skills"; (f) relatedness (adapted from BNSLS): "I can be closer to my friend today" and "Today I am closer to my family". The questionnaire above is used to measure the quality of meeting psychological needs. The instrument rated the participants' level of agreement $(1=$ strongly disagree to $7=$ strongly agree).

The second questionnaire used in this study was nonattachment developed by Sahdra, at al. (2015), namely the NAS-7 scale. This scale has sample items such as: "I can let go of regret and dissatisfaction about the past" and "I can enjoy a pleasant experience without needing it to last forever". Responses from this scale range from "Strongly Disagree" to "Very Agree".

The measurement of well-being consisted of a brief measurement of the aspects of emotional well-being, psychological well-being and social well-being as measured by Mental Health Continuum (MHC-SF). The MHC-SF consisted of three statements measuring emotional well-being (happiness, interest in life, and life satisfaction), six items measuring psychological well-being namely self-acceptance, mastery environment, positive relationships with others, personal growth, autonomy, purpose in life; and social well-being comprised five statements measuring social contribution, social integration, social actualisation, social acceptance, and social 
coherence. The response range on the MHC-SF scale consists of "Never" = 1 to "Every Day" = 6 . The variable mindfulness was measured by the Mindful Attention Awareness Scale (MAAS) (Brown \& Ryan, 2003) consisted of 15 statements in one factor. An example of a statement from mindfulness is: "I can experience emotions by not realizing it until some time later", "I find it difficult to focus/concentrate on what is happening now" and "I tend to walk quickly toward my goal, without pay attention to what I've experienced along the way". The MAAS was measured in 6-point response scale $(1=$ almost always, $2=$ very frequently, $3=$ somewhat frequently, $4=$ somewhat infrequently, 5 = very infrequently, and $6=$ almost never).

\subsection{Results}

The following was a description of the research variables based on mean values and standard deviations. This description meant that participants had a relatively high nonattachment. The quality of maternal relations was also high because $\mathrm{M}=4.236>\mathrm{Me}=3$. Participant mindfulness trait was high because $\mathrm{M}=3.686>\mathrm{Me}=3.5$. Daily psychological needs satisfaction and daily well-being participants were also high because $\mathrm{M}>\mathrm{Me}=4$. Table 1 reported the variable descriptive statistics.

Table 1. Research variable descriptive statistics

\begin{tabular}{lll}
\hline Variable & Mean & SD \\
\hline Nonattachment & 3.969 & .724 \\
Trait mindfulness & 3.686 & .817 \\
Daily psychological needs satisfaction & 4.321 & .719 \\
Daily well-being & 4.208 & .843 \\
\hline
\end{tabular}

Data analysis was carried out with the SMART PLS 3.2.8 program (Ringle, Wende \& Becker, 2015) to see the direct effect of trait mindfulness toward nonattachment, indirect effect toward daily psychological needs satisfaction and daily well-being. Data analysis included measurement model and the structural model.

\subsection{Measurement model}

Calculation of the measurement model produced composite reliability values and the average variance extracted (AVE) values as indicators of convergent validity. A path weighting scheme was used to test the outer model (Garson, 2012; Hair et al., 2012) for the PLS-SEM algorithm with a total iteration of 300 . Outer model analysis began by testing composite reliability and discriminant validity representing latent variables. The value limit for outer loading used in this study was .6 (Hair et al., 2011). In order to improve the fitness of the model, items with outer loading smaller than .6 were excluded from the analysis. After all the outer loading had met the criteria, the composite reliability value and construct discriminant validity were obtained. Criteria for composite reliability were $>.6$ for exploration studies and $>.7$ for confirmatory research (Hair et al., 2012). All construct sizes showed good composite reliability (CR) and good convergent validity (AVE). In conclusion, this research showed good measurement model. The summary of the measurement model analysis is shown in Table 2.

Table 2. The measurement model test

\begin{tabular}{|c|c|c|c|}
\hline Variable & & Composite Reliability (CR) & $\begin{array}{l}\text { Average Variance Extracted } \\
\text { (AVE) }\end{array}$ \\
\hline Daily well-being & & .924 & .752 \\
\hline Trait mindfulness & & .825 & .542 \\
\hline Nonattachment & & .779 & .541 \\
\hline $\begin{array}{l}\text { Daily psychological } \\
\text { satisfaction }\end{array}$ & needs & .798 & .570 \\
\hline
\end{tabular}




\subsubsection{Discriminant validity}

Discriminant validity testing has been a prerequisite for calculating the relationship between variables. If discriminant validity is found, the researcher can be sure that the results of hypothesized structural pathways are real. Discriminant validity test was based on the value of HTMT (Hetero-Trait-Mono-Trait). All values in the confidence interval (CI) 97.5\% should not approach the value 1 to claim discriminant validity (Henseler, Ringle \& Sarstedt, 2015). In this study, all constructs indicate no threat to discriminant validity because all constructs had an HTMT value of $\mathrm{X}<0.90$.

Table 3. The HTMT value of variables discriminant validity

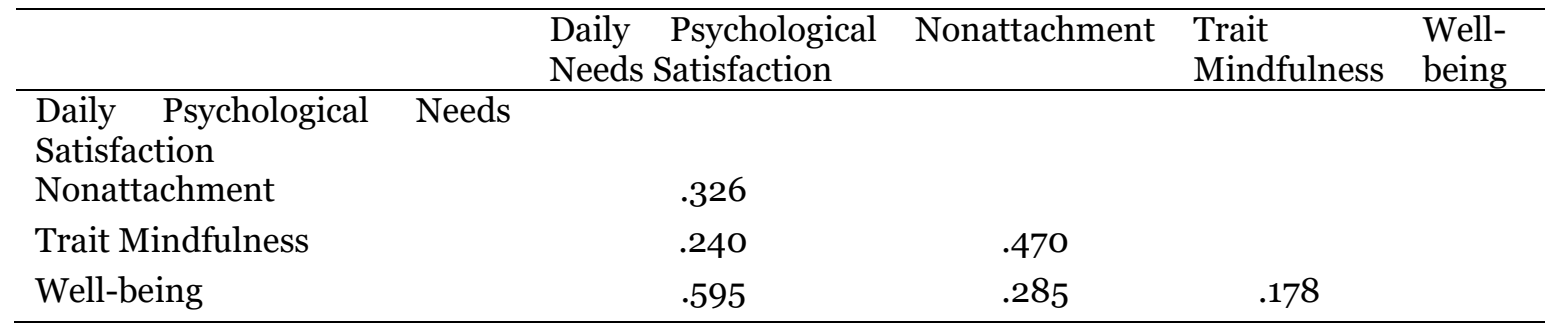

\subsubsection{Goodness of fit}

The research goodness of fit test was based on the standardized square root mean residual SRMR value. The SRMR was based on changes in both the sample covariance matrix and the covariance matrix predicted into the correlation matrix. SRMR was defined as the difference between the observed correlation and the implied correlation matrix model. Thus, it was possible to assess the average difference between the observed and expected correlations as the absolute measure of the appropriate criteria (model). SRMR values less than .10 was considered fit (Hu \& Bentler, 1999). Henseler et al. (2014) introduced SRMR as a goodness of fit measure for PLS-SEM which could be used to avoid model misspecification. This research model produced an SRMR (estimated model) value of .087, which indicated a good fit model.

\subsection{The structural model test (inner model)}

The hypothesis testing of the study was carried out by bootstrapping analysis which resulted in path coefficient values as shown in Table 4. Based on the T-Statistics significance criteria $>1.96$, it could be seen that only mindfulness traits which had no significant effect on daily psychological needs satisfaction $(1.25>1.96)$. This meant that the hypothesis related to mindfulness predictions against daily psychological needs satisfaction was not accepted. The path prediction of daily psychological needs satisfaction toward daily well-being was confirmed $(1.96<$ 9.748). Nonattachment verified its prediction over daily psychological needs satisfaction $(1.96<$ 2.218). Lastly, trait mindfulness predicted nonattachment $(1.96<4.622)$. Table 4 summarized the path coefficients and descriptive statistics.

Table 4. The path coefficients between variables

\begin{tabular}{|c|c|c|c|c|c|}
\hline & $\begin{array}{l}\text { Original } \\
\text { Sample } \\
\text { (O) }\end{array}$ & $\begin{array}{l}\text { Sample } \\
\text { Mean } \\
\text { (M) }\end{array}$ & $\begin{array}{l}\text { Standard } \\
\text { Deviation } \\
\text { (STDEV) }\end{array}$ & $\begin{array}{l}\text { Tr Statistics } \\
(|\mathrm{O} / \mathrm{STDEV}|)\end{array}$ & $\begin{array}{l}\text { P } \\
\text { Values }\end{array}$ \\
\hline $\begin{array}{l}\text { Daily Psychological Needs } \\
\text { Satisfaction -> Well-being }\end{array}$ & .480 & .489 & .046 & 10.380 & .000 \\
\hline $\begin{array}{l}\text { Nonattachment } \quad->\quad \text { Daily } \\
\text { Psychological Needs Satisfaction }\end{array}$ & .184 & .186 & .074 & 2.473 & .014 \\
\hline $\begin{array}{l}\text { Trait Mindfulness } \\
\text { Nonattachment }\end{array}$ & .311 & .333 & .062 & 5.055 & .000 \\
\hline
\end{tabular}




\subsubsection{Specific indirect effects}

Based on bootstrapping testing, the results showed that nonattachment mediated the path of mindfulness towards daily psychological needs satisfaction. Variables nonattachment and daily psychological needs satisfaction did not mediate the relationship between mindfulness traits and daily wellbeing. The indirect effect of daily psychological needs satisfaction was also not significant in the relationship between trait mindfulness and daily well-being. Table 5 shows the value of T-Statistics $<1.96$.

Table 5. Specific indirect effect

\begin{tabular}{|c|c|c|c|c|c|}
\hline Path & $\begin{array}{l}\text { Original } \\
\text { Sample (O) }\end{array}$ & $\begin{array}{l}\text { Sample } \\
\text { Mean } \\
\text { (M) }\end{array}$ & $\begin{array}{l}\text { Standard } \\
\text { Deviation } \\
\text { (STDEV) }\end{array}$ & $\begin{array}{l}\text { T } \quad \text { Statistics } \\
(|\mathrm{O} / \mathrm{STDEV}|)\end{array}$ & P Values \\
\hline $\begin{array}{lrr}\text { Trait Mindfulness } & -> \\
\text { onattachment } & -> & \text { daily } \\
\text { Psychological } & & \text { Needs } \\
\text { Satisfaction } & & \end{array}$ & .057 & .062 & .027 & 2.116 & .035 \\
\hline $\begin{array}{l}\text { Nonattachment } \rightarrow \text { daily } \\
\text { psychological needs } \\
\text { satisfaction }->\text { well-being }\end{array}$ & .088 & .091 & .038 & 2.330 & .020 \\
\hline 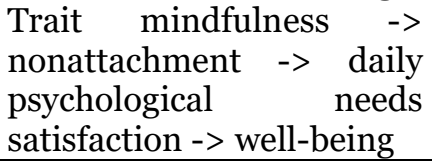 & .028 & .030 & .014 & 1.978 & .048 \\
\hline
\end{tabular}

\subsubsection{F square (F2) test}

Cohen (1988) stated that reporting effect size was important in the analysis to see the extent to which the null hypothesis was wrong. Vacha-Haase and Thompson (2004) stated that effect size was a statistic that calculated the extent to which the results of the analysis in the study sample deviated from expectations, especially related to the null hypothesis. Another opinion expressed by Kirk (1996) who sees effect size as a number that showed the practical role of an effect. This practical utility aimed to be used as a basis for making various policies or practical matters. To see the effect size criteria, the criteria from Cohen (1988) were used, namely $\mathrm{F}^{2}<.02$ (small), . $15<\mathrm{F}^{2}<.3$ (moderate) and $.3<\mathrm{F}^{2}$ (strong). Based on the above criteria, the effect size nonattachment on daily psychological needs satisfaction (.035) was small, the effect size mindfulness trait on nonattachment (.107) was small, and daily psychological needs satisfaction against daily wellbeing (.300) was moderate. These findings showed that only the relationship between daily psychological needs satisfaction and daily wellbeing had a mild and meaningful effect size.

Table 6. The F square test

\begin{tabular}{llccc}
\hline & $\begin{array}{l}\text { Daily Psychological Needs } \\
\text { Satisfaction }\end{array}$ & Nonattachment & $\begin{array}{l}\text { Trait } \\
\text { Mindfulness }\end{array}$ & $\begin{array}{c}\text { Well- } \\
\text { being }\end{array}$ \\
\hline $\begin{array}{l}\text { Daily Psychological } \\
\text { Needs Satisfaction }\end{array}$ & & & & .300 \\
Nonattachment & .035 & & \\
Trait Mindfulness & & .107 & \\
Well-being & & & \\
\hline
\end{tabular}




\subsubsection{Multiple Group Analysis (MGA)}

In this study, multiple group analysis was used to test differences of coefficients path from two groups of data: gender and meditation practice. The result of MGA test of gender was as follows.

Table 7. Multiple group analysis based on gender

\begin{tabular}{lcc}
\hline Path & $\begin{array}{l}\text { Path Coefficients-diff } \\
(\mid \text { Female - Male |) }\end{array}$ & $\begin{array}{l}\text { P-Value } \\
\text { (Female vs Male) }\end{array}$ \\
\hline $\begin{array}{l}\text { Daily Psychological Needs Satisfaction }-> \\
\text { Well-being }\end{array}$ & .072 & .721 \\
$\begin{array}{l}\text { Nonattachment -> Daily Psychological Needs } \\
\text { Satisfaction }\end{array}$ & .141 & .168 \\
Trait Mindfulness -> Nonattachment & .139 & .087 \\
\hline
\end{tabular}

The result showed that gender did not differentiate path coefficients between variables studied because the $P$ value was greater than .05. It means that the prediction of daily psychological needs satisfaction toward well-being is the same for both male and female participants. For both male and female participants, their daily psychological needs satisfaction is predicted from their nonattachment. Lastly, all participants' mindfulness trait predicts their nonattachment.

Table 8. Multiple group analysis based on meditation practice

\begin{tabular}{|c|c|c|}
\hline Path & $\begin{array}{l}\text { Path Coefficients-diff } \\
\text { (|Meditation-No } \\
\text { Meditation|) }\end{array}$ & $\begin{array}{l}\text { p-Value(Meditation) vs No } \\
\text { Meditation }\end{array}$ \\
\hline $\begin{array}{l}\text { Daily Psychological Needs Satisfaction } \\
\text {-> Well-being }\end{array}$ & .067 & .756 \\
\hline $\begin{array}{l}\text { Nonattachment -> Daily Psychological } \\
\text { Needs Satisfaction }\end{array}$ & .074 & .697 \\
\hline Trait Mindfulness -> Nonattachment & 214,. & .019 \\
\hline
\end{tabular}

The experience of participants' meditation which was categorized into two categories: meditate and never meditate also showed no different path coefficients as indicated the $P$ values above .05. In summary, the meditation practices do not differentiate Table 7 summarized the results.

\subsection{Discussion}

The instruments of nonattachment, trait mindfulness, basic psychological needs satisfaction, and daily well-being show good psychometric properties of reliability and convergence validity. Thus, the use of these instruments is then endorsed to study the Buddhist's contribution to human mental health and welfare.

Based on the analysis with partial least square (PLS) approach, daily psychological needs satisfaction predicts daily well-being. This finding confirms the findings of Reis et al. (2000) and Sheldon et al. (1996). Individuals with higher relatedness and self-determination reported higher well-being and vitality when they experienced greater relatedness and autonomy.

Daily psychological needs satisfaction positively predicted participants' subjective well-being (life satisfaction and happiness). Vansteenkiste et al. (2006) found that the total satisfaction score of basic psychological needs positively related to well-being among Chinese students studying in Denmark. The basic psychological needs satisfaction also correlated positively with happiness and self-actualization in women who worked as models in England, positively associated with happiness, self-actualization, and life satisfaction in women who did not 
work as models in the United Kingdom (Meyer et al., 2007). In contrast, psychological needs satisfaction when represented by total needs scores were negatively associated with depression in Chinese students studying abroad (Vansteenkiste et al., 2006) and anxiety, depression, and loss of confidence in women who worked as models in the United Kingdom (Meyer et al., 2007). Thus, the external relations associated with the total needs satisfaction score seem to support the definition of SDT satisfaction needs (i.e., a higher level of satisfaction needs are positively related to well-being and negatively related to the measurement of ill-being).

The hypothesis related to the prediction of mindfulness towards nonattachment cannot be rejected. Sahdra et al. (2010) reported that the Buddhist concept of nonattachment (Sanskrit: viraga) was positively related to mindfulness and psychological well-being. Sahdra et al. conceptualizing nonattachment as "lack of fixation, nonreactivity, faster recovery from emotional stress". Nonattachment also has the quality of "not feeling the inner pressure to avoid or be attached to others". With the high nature of mindfulness, nonattachment can increase. The aspect of mindfulness: observing, describing, and acting with awareness, is also related to nonattachment. Before an individual can cling to his unhealthy fiction, he must be aware of it, observe attachments without judging himself too hard, and refrain from reacting impulsively. Thus, mindfulness is conducive to increase individual nonattachment.

The last finding reveals the prediction of nonattachment toward daily psychological needs satisfaction. One of the basic psychological needs is relatedness. The practice of nonattachment brings effect to mental constructions by identifying whether their mental model induces security or induces insecurity. By cultivating nonattachment to our mental construction, then it provides unhealthy fixations on certain objects. From this process, our relatedness becomes a healthy relatedness because it involves the process of "letting go" of relatedness fixations. Individuals with higher nonattachment are then experiencing higher satisfaction in their basic psychological needs.

However, when the demographic aspect of gender was included in the multi-group analysis (MGA), there was no difference in predictions of daily psychological needs satisfaction toward daily well-being and nonattachment prediction toward daily psychological needs satisfaction. The only difference found in the study was on the path coefficients of trait mindfulness towards nonattachment.

Mindfulness interventions which can be in the form of formal meditation or through practice in everyday life, are believed to elevate nonattachment. Usually, meditators tend to show better quality on nonattachment than non-meditators (Sahdra et al., 2010). The status of meditators and nonmeditators in this study distinguishes the predictions of mindfulness toward nonattachment. It proves that the meditator quality and type of meditation have an impact on the moderating the predictions of mindfulness toward nonattachment. With the process of meditation, individual practices the "let it go" skills so that individual is no longer attached with objects in life and finally increasing happiness and well-being.

\section{Conclusions}

Study involving nonattachment is relatively rare and hardly found in Western and Eastern Psychology. This study confirms previous findings regarding the prediction of trait midfulness toward nonattachment, psychological needs satisfaction prediction toward human's subjective well-being (life satisfaction and happiness), as well as the nonattachment as mediator between trait mindfulness and well-being. The meditation experiences also increases the participants' nonattachment through the practice of "let it go" mechansism. 


\section{Acknowledgements}

The author expresses gratitude to Biksuni Bhadrasatyani Shakya / Shi Xian Yi Satyani of Sangha Agung Indonesia for contributing ideas and in the research. This research was supported by DPPM Tarumanagara University.

The author declares no competing interests.

\section{References}

Black, D. S. (2013). Mindfulness research guide. From www.mindfulexperience.org.

Bodhi, B. (1984). The noble eightfold path: Way to the end of suffering. Buddhist Publication Society.

Brown, K. W., \& Ryan, R. M. (2003). The benefits of being present: mindfulness and its role in psychological well-being. Journal of personality and social psychology, 84(4), 822.

Brown, K. W., Ryan, R. M., \& Creswell, J. D. (2007). Mindfulness: theoretical foundations and evidence for its salutary effects. Psychological Inquiry, 18(4), 211-237.

Chen, Y. (2006). Coping with suffering: The Buddhist perspective. In P. T. P. Wong \& L. C. J. Wong (Eds.), Handbook of multicultural perspectives on stress and coping (pp. 73-89). Dallas, TX: Spring.

Chiesa, A., \& Serretti, A. (2010). A systematic review of neurobiological and clinical features of mindfulness meditations. Psychological Medicine, 40(8), 1239-1252.

Coffey, K. A., \& Hartman, M. (2008). Mechanisms of action in the inverse relationship between mindfulness and psychological distress. Journal of Evidence-Based Complementary \& Alternative Medicine, 13(2), 79-91.

Cohen, J. (1988). Statistical power analysis for the behavioral sciences ( $2^{\text {nd }}$ ed.). New York, NY: Academic Press.

Creswell, J. D., Way, B. M., Eisenberger, N. I., \& Lieberman, M. D. (2007). Neural correlates of dispositional mindfulness during affect labeling. Psychosomatic Medicine, 69(6), 560-565.

Deci, E. L., \& Ryan, R. M. (1985). The general causality orientations scale: Self-determination in personality. Journal of Research in Personality, 19, 109-134.

Deci, E. L., \& Ryan, R. M. (200o). The "what" and "why" of goal pursuits: Human needs and the selfdetermination of behavior. Psychological Inquiry, 11, 227-268.

Fletcher, L. B., Schoendorff, B., \& Hayes, S. C. (2010). Searching for mindfulness in the brain: A processoriented approach to examining the neural correlates of mindfulness. Journal of Mindfulness, $1,41-63$.

Garson, G. D. (2012). Partial least squares. "Blue Book", Statistical Associates Publishing.

Greeson, J. M. (2009). Mindfulness research update: 2008. Complementary Health Practice Review, 14(1), $10-18$.

Hair, J. F., Ringle, C. M., \& Sarstedt, M. (2011). PLS-SEM: Indeed, a silver bullet, Journal of Merketing Theory and Practice, 19(2), 139-150.

Hair, J. F., Sarstedt, M., Ringle, C. M., and Mena, J. A. (2012). An assessment of the use of partial least squares structural equation modelling in marketing research, Journal of the Academy of Marketing Science, 4O(1), 414-433.

Harter, S. (1978). Effectance motivation reconsidered: Toward a developmental model. Human Development, 21, 34-64 
Henseler, J., Ringle, C. M., \& Sarstedt, M. (2015). A new criterion for assessing discriminant validity in variance-based structural equation modeling, Journal of the Academy of Marketing Science, $43(1), 115-135$.

Hayes, S. C. (2002). Buddhism and acceptance and commitment therapy. Cognitive and Behavioral Practice, 9, 58-66. http://doi.org/10.1016/S1077-7229(02)80041-4

Hofmann, S. G., Sawyer, A. T., Witt, A. A., \& Oh, D. (2010). The effect of mindfulness-based therapy on anxiety and depression: A meta-analytic review. Journal of Consulting and Clinical Psychology, 78(2), 169-183.

Howell, A. J., Digdon, N. L., Buro, K., \& Sheptycki, A. R. (2008). Relations among mindfulness, well-being, and sleep. Personality and Individual Differences, 45(8), 773-777.

Kabat-Zinn, J. (2003). Mindfulness-based interventions in context: Past, present, and future. Clinical Psychology: Science and Practice, 10, 144-156.

Kabat-Zinn, J., \& Hanh, T. N. (2009). Full catastrophe living: Using the wisdom of your body and mind to face stress, pain, and illness. New York, NY: Delta.

Kashdan, T. B., Julian, T., Merritt, K., \& Uswatte, G. (2006). Social anxiety and posttraumatic stress in combat veterens: Relations to well-being and character strengths. Behavior Research and Therapy, 44, 561-583.

Keng, S. L., Smoski, M. J., \& Robins, C. J. (2011). Effects of mindfulness on psychological health: A review of empirical studies. Clinical Psychology Review, 31(6), 1041-1056.

Kirk, R. E. (1996). Practical significance: A concept whose time has come. Educational and Psychological Measurement, 56, 746-759. http://doi.org/10.1177/0013164496056005002

Meyer, B., Enstrom, M. K., Harstveit, M., Bowles, D. P., \& Beevers, C. G. (2007). Happiness and despair on the catwalk: Need satisfaction, well-being, and personality adjustment among fashion models. The Journal of Positive Psychology, 2, 2-17.

Mikulas, W. (2007). Buddhism and Western psychology: Fundamentals of integration. Journal of Consciousness Studies, 14, 4-49.

Ñanamol, B., \& Bodhi, B. (1995). The middle length discourses of the Buddha: a translation of the Majjhima Nikāya. Somerville: Wisdom Publications.

National Research Council. (2013). Subjective well-being: Measuring happiness, suffering, and other dimensions of experience. Panel on measuring subjective well-being in a policy-relevant framework. In A. A. Stone, \& C. Mackie (Eds.), Committee on national statistics, division of behavioral and social sciences and education. Washington, DC: The National Academies Press.

Reis, H. T., Sheldon, K. M., Gable, S. L., Roscoe, J., \& Ryan, R. M. (2000). Daily well-being: The role of autonomy, competence, and relatedness. Personality and Social Psychology Bulletin, 26, 419435 .

Ringle C. M., Wende, S., \& Becker, J. M. (2015). SmartPLS 3. www.smartpls.com

Ryan, R. M. (1995). Psychological needs and the facilitation of integrative processes. Journal of Personality, $63,397-427$

Ryan, R. M., \& Deci, E. L. (2002). Overview of self-determination theory: An organismic dialectical perspective. In E. L. Deci \& R. M. Ryan (Eds.), Handbook of self-determination research (pp. 3-33). Rochester, NY: University of Rochester Press.

Sahdra, B. K., Shaver, P. R., \& Brown, K. W. (2010). A scale to measure nonattachment: A Buddhist complement to Western research on attachment and adaptive functioning. Journal of Personality Assessment, 92, 116-127. http://doi.org/10.1080/00223890903425960 
Sahdra, B. K., Ciarrochi, J., Parker, P. D., Marshall, S., \& Heaven, P. (2015). Empathy and nonattachment independently predict peer nominations of prosocial behavior of adolescents. Frontiers in Psychology, 6, 263.

Sahdra, B., Ciarrochi, J., \& Parker, P. (2016). Nonattachment and mindfulness: related but distinct constructs. Psychological Assessment, 28(7), 819.

Santorelli, S.F., \& Kabat-Zinn, J. (2013). Stress reduction program. Retrieved September 11, 2013, from http://umassmed.edu/uploadedFiles/cfm2/SRP for_desktop_printing.pdf.

Schmidt, S. (2011). Mindfulness in East and West - Is it the same? In H. Walach, S. Schmidt, \& W.B. Jonas (Eds.), Neuroscience, consciousness, and spirituality. New York: Springer.

Schuhmacher, S., \& Woerner, G. (Eds.). (1994). The encyclopedia of eastern philosophy and religion. Boston: Shambhala.

Shapiro, D. H. (1992). A preliminary study of long-term meditators: Goals, effects, religious orientation, cognitions. The Journal of Transpersonal Psychology, 24(1), 23-39.

Smith, J. E., Richardson, J., Hoffman, C., \& Pilkington, K. (2005). Mindfulness-based stress reduction as supportive therapy in cancer care: Systematic review. Journal of Advanced Nursing, 52(3), 315-327.

Tsering, G. T. (2005). The foundation of Buddhist thoughts: The Four Noble Truths. Boston: Wisdom Publications.

Vansteenkiste, M., Lens, W., Soenens, B., \& Luyckx, K. (2006). Autonomy and relatedness among Chinese sojourners and applicants: Conflictual or independent predictors of well-being and adjustment? Motivation and Emotion, 30, 273-282.

Veenhoven, R. (1996). The study of life satisfaction. In W. E. Saris, R. Veenhoven, A. C. Scherpenzeel \& B. Bunting (Eds.), A comparative study of satisfaction with life in Europe. Eötvös University Press.

Wallace, A. (1999). The Buddhist tradition of Samatha: Methods for refining and examining consciousness. Journal of Consciousness Studies, 6(2), 175-187.

Wallace, A. B., \& Bodhi, B. (2006). The nature of mindfulness and its role in Buddhist meditation: A correspondence between B. Alan Wallace and the Venerable Bhikkhu Bodhi.

Wallace, A., \& Shapiro, S. L. (2006). Mental balance \& Well-Being: building bridges between Buddhism and Western psychology. American Psychologist, 61(7), 690-701.

Wang, S. Y., Wong, Y. J., \& Yeh, K. H. (2016). Relationship harmony, dialectical coping, and nonattachment: Chinese indigenous wellbeing and mental health. The Counseling Psychologist, 44(1), 78-108. 